\title{
The prevalence of complementary and alternative medicine use in the general population of Babol, North of Iran, 2018
}

\author{
Reihaneh Moeini ${ }^{1}$, Seyyed Ali Mozaffarpur ${ }^{1}$, Morteza Mojahedi', Seyed Davoud Nasrolahpour Shirvani²,
} Narjes Gorji ${ }^{1}$, Roshanak Saghebi ${ }^{3}$, Farid Abolhassani Shahreza ${ }^{4}$ and Hoda Shirafkan ${ }^{5^{*}}$ (1)

\begin{abstract}
Background: Complementary and Alternative Medicine (CAM) have recently become more popular and accepted worldwide. One principal step to identify the status and organize strategies of CAM is evaluating the manner and the prevalence of its usage among people. This study aimed to investigate the prevalence of CAM modalities usage by the people of Babol, a central city in the North of Iran, in 2018.

Methods: Using the original International CAM Questionnaire (I-CAM-Q), a questionnaire was redesigned in Persian (Farsi) with some changes such as adding special modalities in Iran and its validity and reliability were assessed. Six hundred households were evaluated using a cluster sampling method in 2018 spring by 12 trained interviewers.

Results: Finally, 1770 questionnaires were correctly completed. A total of 110 participants (6.21\% of the completed questionnaires) had visited CAM therapists in the last year, 109 persons (6.15\%) had received prescriptions from physicians and paramedics to use CAM, and a total of 1032 people $(58.30 \%)$ used herbs and herbal medicines in the last 12 months. Also, 1265 individuals (71.46\%) had used CAM throughout their lives. The most popular methods were herbal medicine (65.76\%), Persian Medicine (13.78\%), water therapy (10.45\%) and music therapy (8.36\%). The use of CAM was more popular among women.

Conclusions: The general use of CAM in Babol was similar to other studies, but there were fewer visits by CAM therapists and less frequent adoption of common methods including homeopathy, acupuncture, and energy therapy. It was found that CAM was mostly used for non-serious diseases such as cold and transient gastrointestinal disorders, a pattern that is different from other studies in this field.
\end{abstract}

Keywords: Persian medicine, Complementary therapies, I-CAM-Q

\section{Background}

Complementary and Alternative Medicine (CAM) is commonly considered as therapeutic approaches which is not part of conventional medicine [1]. Herbal medicine, traditional medicine, homeopathy, chiropractic, acupuncture, reflexology, and massage are among the

\footnotetext{
* Correspondence: hodashirafkan@gmail.com

${ }^{5}$ Social Determinants of Health Research Center, Health Research Institute, Babol University of Medical Sciences, Babol, Iran

Full list of author information is available at the end of the article
}

most well-known CAM modalities all over the world. CAM has become more popular and accepted in recent decades in both developed and developing countries [2]. In such instances, $74 \%$ of Canadians and $60 \%$ of Chinese have had the experience of using CAM methods [3]. The prevalence of CAM is not directly comparable across countries and surveys due to various definitions and instruments used. Also, cultural and socioeconomic factors determine various trends in CAM use; as an example, the use of CAM in 1 year in Europe was reported from

(c) The Author(s). 2021 Open Access This article is licensed under a Creative Commons Attribution 4.0 International License, which permits use, sharing, adaptation, distribution and reproduction in any medium or format, as long as you give appropriate credit to the original author(s) and the source, provide a link to the Creative Commons licence, and indicate if changes were made. The images or other third party material in this article are included in the article's Creative Commons licence, unless indicated otherwise in a credit line to the material. If material is not included in the article's Creative Commons licence and your intended use is not permitted by statutory regulation or exceeds the permitted use, you will need to obtain permission directly from the copyright holder. To view a copy of this licence, visit http://creativecommons.org/licenses/by/4.0/. The Creative Commons Public Domain Dedication waiver (http://creativecommons.org/publicdomain/zero/1.0/) applies to the data made available in this article, unless otherwise stated in a credit line to the data. 
$10 \%$ in Hungary to almost $40 \%$ in Germany; but, an increasing trend in CAM usage seems to be obvious [4-6]. However, the tendency to use CAM did not grow in all modalities equally [7]. Indeed, cultural and social differences can also affect the choice of the method used [8]. These kinds of medicine are used for various purposes such as therapy, disease prevention and maintenance of well-being [2].

Many studies have been conducted across countries, cities, and continents to determine how people are using these methods and investigate their attitudes towards them [9]. These are the first step in identifying the situation and planning the strategies to promote the safe usage of CAM, as well as preventing or reducing undesirable consequences of these methods. Indeed, the principal step to identify the status and organize strategies of CAM is evaluating the manner and frequency of its usage among people [3].

In Iran, due to the existence of particular traditional medicine [Persian Medicine; PM] with a history of several thousand years, people are still using these methods [10]. Moreover, since 2007, a specialized field of Persian medicine was established as a $\mathrm{PhD}$ program in some medical universities and interested physicians entered this field. Despite that, many non-academical practitioners are active in this field $l$ as medicinal herbs sellers (Attari) or traditional healers such as bone setters who correct joint dislocations and treat musculoskeletal problems. In addition, from 2016, some preventive recommendations of PM entered in the first level of health services in 10 cities of Iran (Health houses) as a pilot study. There are few official therapists in other common methods of CAM in the world such as homeopathy, chiropractic and acupuncture in Iran [11]. Although some studies have been conducted on the use of CAM methods among different patient groups in Iran, studies on the general population are limited, and most of them have used researcher-made questionnaires. Examples include the study by Lotfi et al. in 2014 that examined the extent of the use of different types of CAM by Kashan population and their attitude toward them [3].

Babol city is the oldest city in northern Iran with a history of 3000 years, which had been the capital of Mazandaran province for many years. The first university of medical sciences in northern Iran was established there. Also, currently it has the only university with a faculty of Persian medicine in northern Iran. Furthermore, it was among 10 cities applying PM preventive recommendations in health houses. Babol county includes the city of Babol and several surrounding villages, and it is the most populous county in northern Iran. The population is almost equally divided into city (250000) and village (280000). Considering the lack of studies in this area and the impact of culture on the use of CAM, this study aimed to investigate the prevalence of the use of CAM and its different methods by the people of Babol county (Babol city and its villages(, in 2018, using a standard questionnaire. Moreover, exploration of the relationship between CAM use and user's characteristics as well as data about sources of familiarity with these methods and out-ofpocket spending are other purposes of the study.

\section{Methods \\ The format of the CAM Questionnaire (I-CAM-Q)}

The International CAM Questionnaire (I-CAM-Q) is a unified tool that can provide comparable results for studies conducted worldwide to measure the use of CAM. I-CAM-Q was developed in an international group of CAM researchers as a standardized questionnaire to reduce questionnaire-related bias [12].

Using this questionnaire is common in several surveys on the utilization of CAM conducted in several countries [13-15]. As the type and circumstances of CAM may vary widely based on differences in the cultural backgrounds of each country, an adapted version of the I-CAM-Q is usually developed before implementation [16].

The sections of the Questionnaire together with the procedures of completion were thoroughly described in Quandt et al. study [12]. However, considering that in Iran special methods have been developed due to the prevalent use of PM, using the original I-CAM-Q for a survey of CAM use without adapting it to the Iranian culture did not seem reasonable to the researchers. In addition, according to previous studies, some of the commonly used CAM therapies in Europe or East Asia are not applicable in Iran $[17,18]$. Therefore, it had to be localized; to this end, in the first step, the English questionnaire was translated into Persian and during three sessions with the presence of 5 traditional medical specialists and one health specialist, common Iranian methods were included and uncommon methods were excluded. In Table 1 of the questionnaire, herbalist and spiritual healer were removed and traditional medicine healer, bone setter and massage practitioner were added. In Table 2, manipulation and homeopathy were removed and natural supplement, wet cupping, leech therapy, bloodletting, dry cupping and water therapy, and music therapy were added. In Table 3, homeopathic remedies were removed and oral natural supplement and non-oral natural supplement were added. In Table 4, meditation and relaxation were merged, qigong and visualization were removed and cupping, music-therapy, massage, water therapy, detox pad and PM were added. Also, since the four sections of the original questionnaire considered the use of CAM only over the past year, another section was added with the same pattern for investigating the use of different types of CAM throughout life. 


\section{Assessing validity and reliability}

In order to assess the face validity, a pilot study was carried out with 20 individuals at Babol University of Medical Sciences between Jun. 2018 and Feb. 2018. To prevent any misunderstanding, some terms were revised. After this step, the questionnaire was revised by 10 CAM specialists to confirm the validity. The reliability of the questionnaire was tested by a test-retest method with two stages of completion of the form by 30 participants in a two-week interval via Cronbach's alpha.

In the last part of the questionnaire, a few questions about attitude to CAM, the amount of spending on CAM and familiarity with the methods were added. In this part, if the participants did not use complementary therapies at all, they were asked to choose from three important reasons from available answers. If any of the methods of CAM were used, participants were asked about the reasons for using it, the cost and familiarity with the method.

\section{Sample size calculation}

By the Cochran's formula for sample size calculation in prevalence studies, a minimum sample size of 1537 individuals was calculated. A prevalence of $80 \%$ of CAM use among people according to previous studies in Iran [14], type I error $5 \%$ and precision of $2 \%$ was assumed. Considering a dropping rate of $15 \%$ for incomplete or incorrect questionnaires, the sample size became 1768 individuals. By considering an average family size of three, approximately 600 households were included in this study.

\section{Study population and procedures}

This large population-based study was conducted between April and May 2018 in Babol, Mazandaran, Iran. The participants were all community residents who had been living in Babol, were able to participate in the study, and singed written informed consent. For children under the age of 18 and disabled persons who could not be interviewed, their parents or caregiver sign the written informed consent and also replied the questions. The inhabitants living in students' dormitories, military posts, and nursing homes were excluded.

Based on the recommendations of the World Health Organization and the Demographic and Health Surveys (DHS) Country Planning Implementation Model, this sample size was divided into 60 clusters. The headings of 60 clusters were randomly selected using the latest household census data available at the Babol Health Center covering urban, rural and mobile populations [19]. All of those who were at home at the time of the visit were included in the study. The face-to-face interviews at the participants' homes were conducted by thoroughly trained interviewers.
The purpose of this study was to investigate the use of CAM in all ages, different levels of literacy and urban and rural areas; thus, contrary to the standard questionnaire which was completed in a self-report manner, our questionnaire was completed by trained interviewers via face-to-face interviews. Therefore, twelve interviewers with experience in health censuses were selected by an expert from the health network, and they were trained for $9 \mathrm{~h}$ in three sessions, and then each of them was asked to complete the questionnaires for five cases as the pilot stage and submitted it to the analyst.

\section{Statistical analyses}

The collected data were analyzed by SPSS (version 25). The participants' socio-demographic characteristics include age, gender, marital status, education level, occupation, and insurance type. For descriptive analysis, frequencies (percentage) and means $( \pm$ standard deviation) were calculated. To compare the quantitative explanatory variables in the two groups, we ran t-test and nonparametric test of Mann-Whitney $\mathrm{U}$, and for qualitative variables, we performed chi-square and Fisher exact tests. In order to evaluate the relationship between CAM use and other covariates (including gender, age, education, residency location, and marital status), binary logistic regression was used. Using CAM in the past 12 months was the dependent variable. The backward elimination technique was used to fit the regression model. The adjusted odds ratios (OR) and its 95\% confidence intervals were calculated. The significance level was set to 0.05 .

\section{Ethics and consent}

The research was approved by the research ethics committee of National Institute of Health Research (reference number: IR.TUMS.NIHR.REC.1396.53). The written informed consent was signed by every participant. For disabled persons and children under the age of 15 , their legal guardians or parents signed the informed consent.

\section{Results}

Six teams completed interviews in 23 days in May and April 2018. With reference to 600 households, the initial population was estimated to be 1960 , of which 75 were absent despite repeated visits and 72 were reluctant to cooperate. From the 1813 collected questionnaires, 1770 questionnaires were correctly completed. Totally, 849 participants (47.96\%) lived in the urban areas and 913 (51.58\%) in the rural areas. The average age of participants was $35.53 \pm 20.26$. Eight hundred seventy-nine $(49.66 \%)$ of participants were males and 891 (50.33\%) were females. Two hundred and eighty-five $(16.10 \%)$ of 
them had received a university education (Table 1). According to available population information from the county, the study population was representative to the general population in terms of age, sex and residency, but there is a difference only in terms of education. Indeed, the ratio of people with university education in our study was less than this ratio in the population of the city.

\section{Healthcare provider}

The total number of persons who had visited conventional therapists and CAM therapists during the last year was 1347 (76.10\%) and 110 (6.21\%) respectively. Visiting conventional therapists was significantly more frequent in women $(P=0.037)$. Also, in rural areas, CAM therapists are more commonly referred $(P=0.003)$. The most common cause for visiting by CAM therapists was complications of bone and joint pain (44 visits). Furthermore, among the CAM therapists, visiting traditional therapists was the most frequent. Also, the most common causes of visiting traditional therapists were bone and joint pain, colds and respiratory problems, skin and hair problems, and blood concentrations, respectively. The highest degree of satisfaction with complementary therapists was associated with the two groups of bonesetters (78.57\%) and massagers (71.42\%) (Table 2).

\section{CAM treatments received from physicians}

One hundred and thirty-five prescriptions have been made for 109 persons for the use of CAM therapies by conventional physicians and Paramedics. The most frequent prescriptions were for the use of medicinal herbs and herbal medicines in 61 cases $(3.46 \%$ of all participants), wet cupping in 21 cases $(1.18 \%)$ and water therapy in 19 cases $(1.07 \%)$.

Twenty--eight prescriptions (20.7\% of all prescriptions) were made by a physician specialized in traditional medicine. However, 46 (34.47\%) cases were performed by specialists in other sub-disciplines of medicine, 2 $(1.48 \%)$ by nutritionists and 59 cases by general practitioners and family physicians. (Table 3 ).

\section{Use of dietary supplements}

A total of 1032 people (58.30\%) used herbs and herbal medicines orally in the last 12 months with the aim of treating illness or improving health. Over the past 3 months, 952 (53.78\%) have used this method from which 225 people $(12.71 \%)$ have used medicinal plants daily: $63.46 \%$ for the flu and cold, $30.71 \%$ for the digestive tract problems, $32.7 \%$ for prevention and improvement of health, $12.40 \%$ for the nervous system and psychiatric problems, $7.46 \%$ to make body temperament (Mizaj) cold and $3.77 \%$ to make body temperament warm.
Regarding the herbs, the respondents have used Mentha piperita (20.4\%), thyme (Thymus vulgaris) (11.4\%), Mentha pulegium (11.4\%), Citrus aurantium flower (10.7\%), Cinnamomum zeylanicum (9.8\%), Mentha aquatic (9.4\%), and Echium amoenum (8.7\%). Most of the mentioned plants are grown as wild herbs or cultivated in this area for its favorable climate.

A total of 335 (18.9\%) respondents used a variety of vitamins and minerals. Iron supplements, Ca supplements and folic acid were the most commonly used supplements.

In order to treat, improve, or/and maintain health, $20.6 \%$ of the participants have used natural products in the past year. Three hundred and thirty participants (18.6\%) have used these products in the last 3 months and $74(4.18 \%)$ people used these products on a daily basis.

The typical natural product is honey, which is used 199 times alone or in combination with other products. Of these, 65 cases were lemons and honey, which were used to prevent or treat colds and upper respiratory tract infections. Other consumed natural products to improve health were rock candy and hot water $(n=100,5.64 \%$ of participants), grape juice $(n=37,2.09 \%)$ date sauce $(n=$ $15,0.84 \%)$, red sugar $(n=19,1.07 \%)$, royal jelly $(n=7$, $0.39 \%)$, persimmon juice $(n=11,0.62 \%)$, medlar juice $(n=9,0.50 \%)$ and sesame $(n=7,0.39 \%)$.

Three hundred and seventy-four people $(21.7 \%$ of the total) used medicinal herbs and natural products nonorally, such as ointment, fumigation or smoke. Among these medical herbs, Heracleum persicum smoke (12.9\%, $n=230$ ), Cucurbita pepo (pumpkin) fumigation $(3.4 \%$, $n=77)$, and Eucalyptus fumigation $(0.8 \%, n=15)$ have been used.

Totally, 1177 people (66.6\%) used one of the herbal products and natural food supplements (except minerals and vitamins), either orally or topically in the last 12 months (Table 4).

\section{Self-help practices}

Only a total of $28(1.58 \%)$ persons have used one of the methods listed in Table 3 of original I-CAM questionnaires including yoga (3 persons), relaxation and meditation (2 persons), and prayer therapy (24 persons). Because it was predictable due to cultural differences, other methods had been added, such as music therapy and massage or dry cupping at home by one's own or other relatives. This table also required information on the observance of special dietary guidelines of PM which showed a notable percentage $(10.39 \%, n=184)$ compared to other methods. However, Vow and charity and participating in religious ceremonies obtained the most stats (44.57\%). The highest percentage of good satisfaction (very helpful) was related to music therapy $(78.23 \%, n=$ $115)$, dietary advice $(70.1 \%, n=129)$ and massage $(67.07 \%, n=55)$. (Table 5). 
Table 1 Basic characteristics of participants

\begin{tabular}{|c|c|c|c|}
\hline & Characteristics & frequency & percent \\
\hline \multirow[t]{8}{*}{ Age (year) } & $0-10$ & 211 & 11.92 \\
\hline & $11-20$ & 273 & 15.42 \\
\hline & $21-30$ & 264 & 14.91 \\
\hline & $31-40$ & 303 & 17.11 \\
\hline & $41-50$ & 282 & 15.93 \\
\hline & $51-60$ & 223 & 12.59 \\
\hline & $61-100$ & 200 & 11.29 \\
\hline & Missing data & 14 & 0.79 \\
\hline \multirow[t]{2}{*}{ Sex } & Female & 891 & 50.33 \\
\hline & Male & 879 & 49.66 \\
\hline \multirow[t]{7}{*}{ Education } & Under 7 years old & 135 & 7.62 \\
\hline & Illiterate or Elementary school & 602 & 34.01 \\
\hline & Middle School & 305 & 17.23 \\
\hline & High school & 436 & 24.63 \\
\hline & Associate Degree or bachelor's degree & 242 & 13.67 \\
\hline & Master's degree and higher & 40 & 2.25 \\
\hline & Missing data & 10 & 0.54 \\
\hline \multirow[t]{11}{*}{ Occupation } & Official employee & 93 & 5.36 \\
\hline & Official worker & 27 & 1.46 \\
\hline & Housewife & 559 & 31.58 \\
\hline & Self-employment & 318 & 17.90 \\
\hline & Farmer and gardener & 85 & 4.74 \\
\hline & Retired & 57 & 3.16 \\
\hline & Under 7 age-old & 135 & 7.62 \\
\hline & Student & 347 & 19.54 \\
\hline & Workless & 27 & 1.18 \\
\hline & Other & 99 & 5.31 \\
\hline & Missing data & 13 & 0.73 \\
\hline \multirow[t]{5}{*}{ Marriage status } & Single & 618 & 34.91 \\
\hline & Married & 1066 & 60.22 \\
\hline & Divorced & 14 & 0.79 \\
\hline & Widow and widower & 47 & 2.65 \\
\hline & Missing data & 35 & 1.97 \\
\hline \multirow[t]{5}{*}{ responder } & Him/Her self & 1244 & 70.28 \\
\hline & Parents & 453 & 25.59 \\
\hline & Child & 46 & 2.59 \\
\hline & Supervisor & 21 & 1.18 \\
\hline & Missing data & 6 & 0.33 \\
\hline
\end{tabular}

There was a significant relationship between education level and using music therapy $(P<0.001)$ and dietary recommendations $(p=0.05)$. There was no significant relationship between gender and living area with using any of these methods $(p>0.05)$.
Using logistic regression showed that education, age and sex had a significant relationship with using music therapy.

Other ORs and their 95\% CI were reported in Additional file 1: Appendix 1. 
Table 2 Visit by Healthcare providers in the last year

\begin{tabular}{|c|c|c|c|c|c|c|c|c|}
\hline \multirow[t]{2}{*}{ health care providers } & \multirow[t]{2}{*}{$\begin{array}{l}\text { Visited }^{\mathrm{a}} \\
(\%)\end{array}$} & \multicolumn{3}{|c|}{$\begin{array}{l}\text { Motivation } \\
(\%)^{\mathrm{b}}\end{array}$} & \multicolumn{4}{|c|}{ Helpfulness (\%) } \\
\hline & & $\begin{array}{l}\text { Acute } \\
\text { illness }\end{array}$ & $\begin{array}{l}\text { Long-term } \\
\text { illness }\end{array}$ & $\begin{array}{l}\text { Improvement of well- } \\
\text { being }\end{array}$ & Very & somewhat & $\begin{array}{l}\text { Not at } \\
\text { all }\end{array}$ & $\begin{array}{l}\text { Don't } \\
\text { know }\end{array}$ \\
\hline Family practitioner & $\begin{array}{l}664 \\
(37.51)\end{array}$ & $466(70.18)$ & $158(23.79)$ & $34(5.12)$ & $\begin{array}{l}313 \\
(47.13)\end{array}$ & $303(45.63)$ & $45(6.77)$ & $3(0.45)$ \\
\hline General Physician & $\begin{array}{l}518 \\
(29.26)\end{array}$ & $381(73.55)$ & 12423.93 & $19(3.66)$ & $\begin{array}{l}218 \\
(42.08)\end{array}$ & $285(55.01)$ & $15(2.89)$ & $0(0.00)$ \\
\hline Specialist Physician & $\begin{array}{l}670 \\
(37.85)\end{array}$ & $191(28.50)$ & 419 (62.53) & $14(2.08)$ & $\begin{array}{l}302 \\
(45.07)\end{array}$ & $330(49.25)$ & $11(1.64)$ & $2(0.29)$ \\
\hline Nutritionist & $19(1.07)$ & 6 & 9 & 7 & 11 & 5 & 3 & 0 \\
\hline $\begin{array}{l}\text { Traditional medicine } \\
\text { healer }\end{array}$ & $67(3.78)$ & $19(28.35)$ & $33(49.25)$ & $17(25.37)$ & $21(31.34)$ & $30(44.77)$ & $\begin{array}{l}13 \\
(19.40)\end{array}$ & $3(4.4)$ \\
\hline Acupuncturist & $9(0.50)$ & 2 & 7 & 0 & 5 & 3 & 1 & 0 \\
\hline Bone setter & $14(0.79)$ & 13 & 1 & 0 & 11 & 3 & 0 & 0 \\
\hline Massage practitioner & $14(0.79)$ & 1 & 9 & 4 & 10 & 3 & 1 & 0 \\
\hline Other & $9(0.50)$ & 3 & 4 & 2 & 3 & 3 & 2 & 1 \\
\hline
\end{tabular}

${ }^{\text {a }}$ ercentages are calculated relative to the total sample population (Column percentage)

${ }^{b}$ Percentages are calculated according to the type of health care provider (Row Percentage)

${ }^{c}$ Percentages have been reported only for cases that have used more than 20

\section{Use of complementary medicine throughout life}

As mentioned above, one table was added to the standard questionnaire to examine the extent of using CAM throughout life. More detail was presented in Table 6 and Fig. 1.

There was no significant relationship between age groups, level of education, occupational status, living area and marital status and insurance with life-long CAM usage, but a significant relationship between the use of CAM therapies among two sexes was detected $(\mathrm{p}=0.03)$ in which $63.93 \%(n=562)$ of men and $79.12 \%$ $(n=705)$ of women have used CAM in their lives. Using logistic regression showed that gender and marital status had a significant relationship with using CAM modalities throughout life. Age, education and residency location were removed from the regression model in steps 1,2 and 3 , and it was revealed that men were half as likely to use CAM $(\mathrm{OR}=0.55, p<0.001$, CI: $(0.45,0.67))$ when compared to women. Also, married people used CAM,

Table 3 CAM treatments received by practice or advice of physicians in the last year

\begin{tabular}{|c|c|c|c|c|c|c|}
\hline \multirow[t]{2}{*}{ CAM treatments } & \multirow[t]{2}{*}{ Received } & \multirow[t]{2}{*}{ common reasons for CAM treatments } & \multicolumn{4}{|c|}{ Helpfulness (\%) ${ }^{a}$} \\
\hline & & & Very & Somewhat & $\begin{array}{l}\text { Not at } \\
\text { all }\end{array}$ & $\begin{array}{l}\text { Don't } \\
\text { know }\end{array}$ \\
\hline $\begin{array}{l}\text { Medicinal herbs and herbal } \\
\text { medicine }\end{array}$ & 61 & $\begin{array}{l}\text { Cold and respiratory problems, Musculoskeletal problems, } \\
\text { diabetes }\end{array}$ & $38(62.29)$ & 19(31.14) & $2(3.27)$ & $2(3.27)$ \\
\hline Natural supplement & 11 & Cold, anemia & 10 & 1 & 0 & 0 \\
\hline Wet cupping & 21 & Cough, Musculoskeletal problems, skin problems & $6(28.57)$ & $11(52.38)$ & $4(19.04)$ & $0(0.00)$ \\
\hline Leech therapy & 2 & Musculoskeletal problems, skin problems & 1 & 1 & 0 & 0 \\
\hline Bloodletting & 1 & Blood concentration & 1 & 0 & 0 & 0 \\
\hline Acupuncture & 4 & Weight modification & 2 & 2 & 0 & 0 \\
\hline Yoga & 1 & Relaxation & 1 & 0 & 0 & 0 \\
\hline Massage & 5 & Musculoskeletal problems & 3 & 2 & 0 & 0 \\
\hline Dry cupping & 5 & Musculoskeletal problems & 3 & 2 & 0 & 0 \\
\hline Water therapy & 19 & Musculoskeletal problems & 10 & 7 & 2 & 0 \\
\hline Other & 5 & - & 3 & 2 & 0 & 0 \\
\hline Total & 135 & - & $78(57.77)$ & $47(34.81)$ & $8(5.92)$ & $2(1.48)$ \\
\hline
\end{tabular}

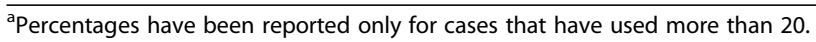


Table 4 Use of dietary supplements in the last year

\begin{tabular}{|c|c|c|c|c|c|c|c|}
\hline \multirow{2}{*}{$\begin{array}{l}\text { Types of dietary } \\
\text { supplements }\end{array}$} & \multirow[t]{2}{*}{ Number } & \multirow[t]{2}{*}{$\%$} & \multirow[t]{2}{*}{ Common reasons } & \multicolumn{4}{|c|}{ Helpfulness } \\
\hline & & & & Very & somewhat & $\begin{array}{l}\text { Not } \\
\text { at } \\
\text { all }\end{array}$ & $\begin{array}{l}\text { Don't } \\
\text { know }\end{array}$ \\
\hline $\begin{array}{l}\text { Oral usage of medicinal } \\
\text { herbs and herbal } \\
\text { medicines }\end{array}$ & 1032 & 58.30 & $\begin{array}{l}\text { flu and cold, digestive tract problems, prevention and improvement } \\
\text { of health, nervous system and psychiatric problems, to change body } \\
\text { temperament }\end{array}$ & 64.92 & 30.03 & 1.9 & 3.15 \\
\hline Vitamins and minerals & 335 & 18.9 & $\begin{array}{l}\text { Musculoskeletal problems, anemia and iron deficiency, general } \\
\text { strengthening and well-being }\end{array}$ & 35.85 & 50.38 & 5.52 & 8.25 \\
\hline $\begin{array}{l}\text { Oral usage of Natural } \\
\text { products }\end{array}$ & 365 & 20.6 & $\begin{array}{l}\text { colds and upper respiratory tract infections, general strengthening } \\
\text { and well-being }\end{array}$ & 67.34 & 13.68 & 8.33 & 10.65 \\
\hline $\begin{array}{l}\text { Non-oral usage of Natural } \\
\text { products }\end{array}$ & 374 & 21.7 & $\begin{array}{l}\text { prevention and maintenance of health, colds and respiratory tract } \\
\text { infections, musculoskeletal and skin disorders }\end{array}$ & 56.20 & 37.59 & 1.27 & 4.94 \\
\hline
\end{tabular}

about $30 \%$ more than the singles $(\mathrm{OR}=1.32, p=0.008$, CI: $(1.08,1.63))$.

Fifty-eight percent $(n=510)$ of men and $73.3 \%(n=$ $654)$ of women had used herbal medicine. This difference was significant as well $(p=0.004)$. Using logistic regression showed that gender had also a significant relationship with using herbal medicine throughout life. Age, education, residency location and marital status were removed from the regression model in steps 2, 3, 4 and 5 and the result revealed that men are half as likely to use CAM (OR $=0.51, p<0.001$, CI: $(0.41,0.62))$ when compared to women.

One hundred and thirteen $(6.4 \%$ of all and $8 \%$ of people over the age of 20) had used wet cupping in which $68.14 \%(n=77)$ of wet cupping users were males and $31.85 \%(n=36)$ were females. In fact, $8.8 \%$ of all men and $4.2 \%$ of women had used this method, which is statistically significant $(p=0.01)$. Seven percent of those who had a history of wet cupping was less than 15 years of age.

Table 5 Self-help practices used in last year

\begin{tabular}{lll}
\hline CAM treatments & Used (\%) & Reasons \\
\hline Cupping & $30(1.69)$ & Musculoskeletal problems \\
Massage & $82(4.63)$ & Musculoskeletal problems \\
$\begin{array}{l}\text { Dietary recommendations } \\
\text { of persian medicine }\end{array}$ & $184(10.39)$ & Gastrointestinal problems \\
Music & $147(8.30)$ & Relaxation \\
Relaxation and Meditation & $2(0.1)$ & Relaxation \\
Yoga & $3(0.15)$ & Relaxation \\
Ti- chi & $0(0.00)$ & - \\
Water therapy & $78(4.40)$ & Musculoskeletal problems \\
Praying & $19(1.07)$ & Disease prevention \\
Vow, charity and participating & $789(44.57)$ & Disease prevention \\
in Religious ceremonies & & \\
Detox pad & $12(0.67)$ & Musculoskeletal problems \\
\hline
\end{tabular}

In our study, a significant difference was seen $(p=$ 0.02 ) between using music-therapy among urban residents $(10.12 \%, n=86)$ and rural residents $(6.79 \%, n=$ $62)$. Also, the level of education significantly influenced the use of music therapy $(p<0.001)$. Furthermore, women $(1.79 \%, \mathrm{n}=16)$ used acupuncture more than men $(0.45 \%, n=4)(p=0.008)$.

Also, 26.5\% $(n=336)$ of users of CAM are under the age of 20 which was mostly due to the use of herbs (88.69\%). Moreover, 6.19\% $(n=30), 3.30 \%(n=16)$ and $1.23 \%(n=6)$ of those less than 20 years had used water therapy, massage and wet cupping respectively.

Using logistic regression showed that dry cupping had a significant relationship with age, and gender, wet cupping with gender, marital status and education, massage with marital status and education, Persian medicine with location, gender and education, music therapy with location, age and education, water therapy with location, education and marital status and acupuncture with age and gender. The ORs were reported in Additional file 1: Appendix 2.

\section{Reasons for using or not using}

Lack of enough information about CAM methods (47.5\%, $n=264)$, no disease and no need for treatment $(32.4 \%$, $n=180)$, and lack of belief in these methods $(29.5 \%, n=$ 164) were the main reasons for not using CAM in people who had never used these methods before.

The most common reasons for using complementary medicine were less complication from these methods $(52 \%, n=637)$, being more effective than the common treatments $(43.2 \%, n=525)$, the usefulness of these methods, the use of conventional medicine $(32.4 \%, n=$ 394 ), and not having serious problem for referring to conventional medicine $(19.6 \%, n=239)$.

\section{Other findings}

In our study, we found that $50.04 \%(n=583)$ of users of medicinal herbs and natural products have satisfied their 
Table 6 Use of complementary medicine throughout life

\begin{tabular}{|c|c|c|c|c|c|c|}
\hline \multirow{2}{*}{$\begin{array}{l}\text { CAM } \\
\text { Methods }\end{array}$} & \multirow{2}{*}{$\begin{array}{l}\text { Frequency } \\
\text { (percent) }\end{array}$} & \multirow[t]{2}{*}{ Common reasons } & \multicolumn{4}{|c|}{ Helpfulness (\%) ${ }^{a}$} \\
\hline & & & Very & Somewhat & $\begin{array}{l}\text { Not at } \\
\text { all }\end{array}$ & $\begin{array}{l}\text { Not } \\
\text { determined }\end{array}$ \\
\hline $\begin{array}{l}\text { Persian } \\
\text { medicine }\end{array}$ & $244(13.78)$ & $\begin{array}{l}\text { Gastrointestinal disorders, Cold and respiratory system disorders, } \\
\text { health improvement }\end{array}$ & $\begin{array}{l}158 \\
(64.75)\end{array}$ & $79(32.37)$ & $2(0.81)$ & $5(2.04)$ \\
\hline $\begin{array}{l}\text { Herbal } \\
\text { medicine }\end{array}$ & $1164(65.76)$ & $\begin{array}{l}\text { Cold and respiratory system disorders, gastrointestinal disorders, } \\
\text { health improvement }\end{array}$ & $\begin{array}{l}711 \\
(61.08)\end{array}$ & $403(34.62)$ & $\begin{array}{l}21 \\
(1.80)\end{array}$ & $29(2.49)$ \\
\hline Wet cupping & $113(6.38)$ & Blood concentration, health improvement, musculoskeletal disorders & $\begin{array}{l}66 \\
(58.40)\end{array}$ & $32(28.31)$ & $\begin{array}{l}10 \\
(8.84)\end{array}$ & $5(4.42)$ \\
\hline Dry cupping & $68(3.84)$ & musculoskeletal disorders, health improvement & $\begin{array}{l}41 \\
(60.29)\end{array}$ & $21(30.88)$ & $6(8.82)$ & $0(0.00)$ \\
\hline Bloodletting & $4(0.22)$ & Blood concentration & 2 & 1 & 1 & 0 \\
\hline Leech-therapy & $21(1.18)$ & musculoskeletal disorders, Blood concentration & $7(33.33)$ & 9 (42.85.) & $1(4.76)$ & $3(14.28)$ \\
\hline Acupuncture & $20(1.12)$ & musculoskeletal disorders, body weight correction & $6(30.00)$ & $7(35.00)$ & $\begin{array}{l}6 \\
(30.00)\end{array}$ & $1(5.00)$ \\
\hline Yoga & $8(0.45)$ & Relaxation and improvement of mental status & 3 & 4 & 1 & 0 \\
\hline Massage & $112(6.32)$ & musculoskeletal disorders & $\begin{array}{l}72 \\
(64.28)\end{array}$ & $35(31.25)$ & $5(4.46)$ & $0(0.00)$ \\
\hline Bonesetter & $21(1.18)$ & musculoskeletal disorders & $\begin{array}{l}13 \\
(61.90)\end{array}$ & $6(28.57)$ & $2(9.52)$ & $0(0.00)$ \\
\hline $\begin{array}{l}\text { Energy } \\
\text { Therapy }\end{array}$ & $4(0.22)$ & Relaxation and improvement of mental status & 1 & 2 & 1 & 0 \\
\hline meditation & $2(0.11)$ & Relaxation and improvement of mental status & 1 & 1 & 0 & 0 \\
\hline Music therapy & $148(8.36)$ & Relaxation and improvement of mental status & $\begin{array}{l}126 \\
(85.13)\end{array}$ & $19(12.83)$ & $0(0.00)$ & $3(2.02)$ \\
\hline Hypnotism & $2(0.11)$ & Relaxation and improvement of mental status & 1 & 1 & 0 & 0 \\
\hline Water therapy & $185(10.45)$ & musculoskeletal disorders, health improvement & $\begin{array}{l}126 \\
(68.10)\end{array}$ & $47(25.40)$ & $1(3.70)$ & $0(0.00)$ \\
\hline praying & $37(2.09)$ & health improvement & $\begin{array}{l}17 \\
(45.94)\end{array}$ & $15(40.54)$ & $0(0.00)$ & $5(13.51)$ \\
\hline Aromatherapy & $3(0.16)$ & Relaxation and improvement of mental status & 2 & 1 & 0 & 0 \\
\hline Homeopathy & $0(0.00)$ & - & 0 & 0 & 0 & 0 \\
\hline Ayurveda & $0(0.00)$ & - & 0 & 0 & 0 & 0 \\
\hline Total CAM & $1265(71.46)$ & & & & & \\
\hline
\end{tabular}

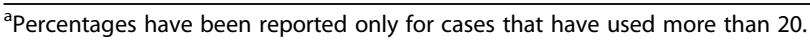

needs by themselves or their relatives. Also, $41.88 \%$ ( $n=$ 488) had bought them from herb seller (attari) and $3.43 \%(n=40)$ from organic product stores.

Seventy-five percent $(N=950)$ of CAM users have paid less than 500.000 Rials for CAM including herbs and natural products. The average cost was about 400, 000 Rials.

Sixty-three percent $(N=799)$ of CAM users selected family and relatives, $37.07 \%(n=469)$ friends and $8.85 \%$ $(n=112)$ listening to radio and television as the method of acquaintance with CAM. Only $3.87 \%(n=49)$ chose virtual space and $4.42 \%(n=56)$ websites.

One hundred and fifty-nine participants (8.98\%) reported receiving health advice based on PM from their local health workers over the past year.

\section{Discussion}

This study is the first population-based Iranian study to have used an edited version of I-CAM questionnaire. The results of this study can be compared with similar studies in two ways: one is a comparison with other Iranian studies that did not use the International Standard Questionnaire and another in comparison with studies of other countries that used the International Questionnaire appropriate to their culture and circumstances.

Comparing the use of different methods of CAM throughout life and in the last year showed that such items as the use of herbal medicine and music therapy have been almost equal, indicating that these methods are part of the lifestyle of these people. However, in cases such as leech therapy, Persian medicine, wet 


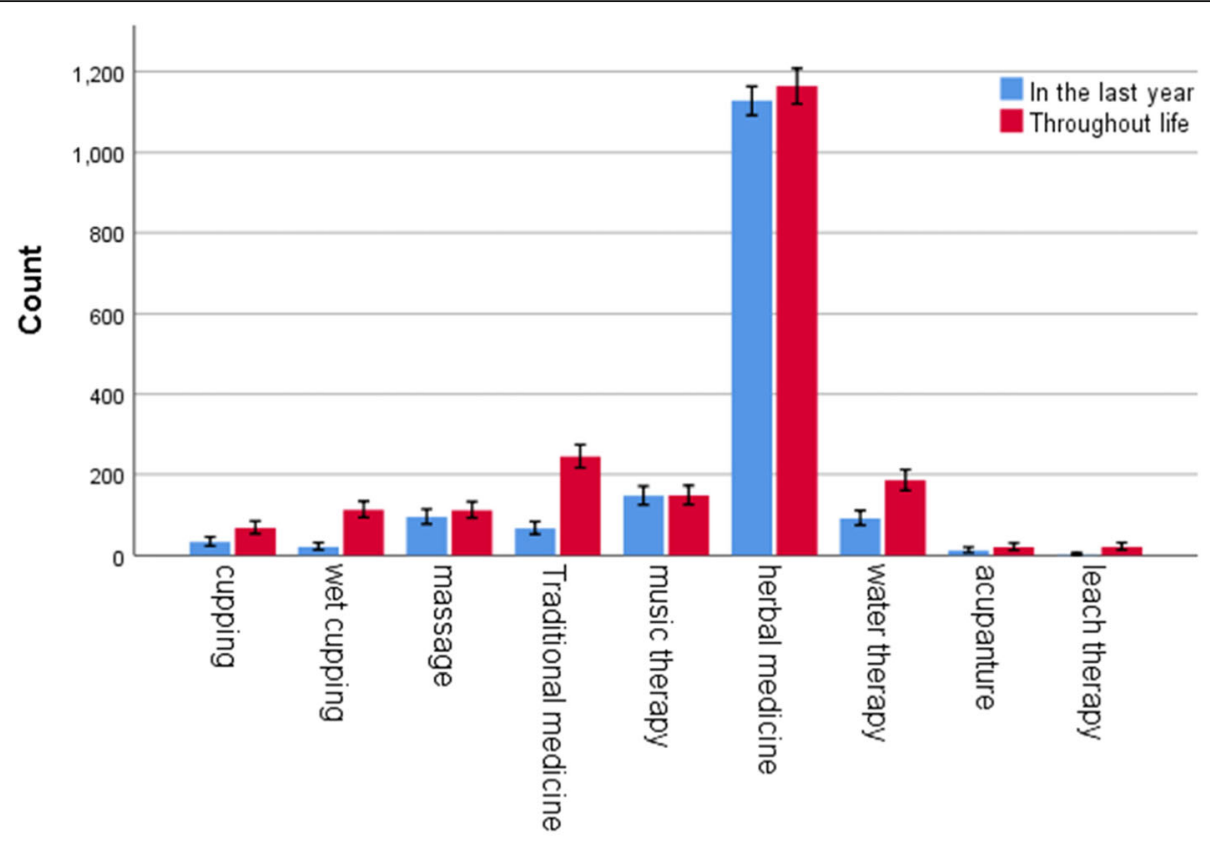

Complementary and Alternative Medicine Modalities

Error bars: $95 \% \mathrm{Cl}$

Fig. 1 Use of Complementary And Alternative Medicine in the last year and throughout life

cupping and acupuncture, which are a type of external intervention and need to see a therapist or service provider, the amount of use during a year will be much less than the use during a lifetime.

\section{Comparison with other Iranian studies}

The results showed that the prevalence of using CAM during life was $71.46 \%$. Prevalence of using medicinal herbs as a typical CAM was about $65.76 \%$ during life and $63.67 \%$ in the last year. Without considering medicinal herbs, the other methods of CAM was found to be $31.8 \%$ throughout life. Persian medicine, wet cupping, dry cupping, music therapy, and hydrotherapy were consecutively less popular.

One study in the capital of Iran (Tehran) in 2008 on 6148 individuals revealed that 66.3 and $52.5 \%$ of the study population have used at least one type of CAM throughout their lives and in the past year, respectively [20]. In another study in the west of Iran (Khorramabad) in 2013, total use of CAM and medicinal plants during lifetime was 79.9 and $69.2 \%$ respectively; furthermore, these were 58.2 and $37.7 \%$ in last year respectively [18]. The results of this study are more similar to the results of our study. However, it is lower for using medicinal plants and higher for energy therapy and prayer therapy. In another Iranian study in the northeast of Iran (Bojnourd) in 2015, 367 individuals were evaluated using clustered sampling. Totally, $84.65 \%$ of the subjects during their lifetime and $76.56 \%$ during the past year had used at least one CAM method [17]. In another study conducted in the center of Iran (Kashan) in 2014, from 576 individuals, $73.75 \%$ had a history of using one type of CAM methods during life. Medicinal plants use was the highest with $68 \%$, and then there were cupping, massage and hydrotherapy [3]. The results of this study are nearly identical to ours. Generally, the results of the present study seem to be more similar to those of the studies conducted during the last 5 years. This may be due to the increased application and advertising of CAM in Iran. However, the use of chiropractic, homeopathy, hypnosis, and energy therapy in Babol is less than that in other cities that evaluated these methods. Lack of familiarity with these methods may be related to education level, as more than $50 \%$ of the study population of Bojnourd had a university education and only $17.5 \%$ were under diploma, but in Babol's study only $16.1 \%$ of sample study (20.7\% of those over 15 years old) had a university education. Also, the use of wet cupping in this study has been reported lower than some other studies in Iran $[17,18]$.

The reasons for using CAM methods such as wet and dry cupping as well as massage, in our study, have been similar to different studies, but the reasons for using other methods, such as herbs in the Babol study, are more similar to those in Bojnourd, where colds and gastrointestinal problems are at the forefront [17]. 
In a Subgroup analysis, there were significant differences between the use of medicinal herbs, acupuncture, and cupping by gender; the use of massage by marriage status; the use of music therapy by the living area and level of education; and the use of water therapy by marriage status and living area. Overall, the use of CAM, herbs, and acupuncture was higher in women and cupping in men. In Khorramabad study, most of the methods (except cupping) including medicinal herbs were significantly higher in women as well, and the use of acupuncture, yoga and energy therapy differed significantly between urban and rural communities. The use of acupuncture has also been more prevalent in collegeeducated people [18].

\section{Comparison with studies of other countries}

The rate of the visit with one of the CAM therapists in this study was $6.2 \%$ which adds up to about $30 \%$ by adding medicinal herbs seller. Meanwhile, the visit with the conventional therapists was $76.6 \%$.

A 2013 study by Albedah et al., using an edited version of I-CAM questionnaire in Kasim, Saudi Arabia, showed that $47.6 \%$ of participants had visited CAM providers in the last year (by eliminating prayer therapists). Visiting herbal medicine providers, honey vendors and wet cupping providers are the most frequent. The rate of visit with conventional medicine therapists was $83.4 \%$ [21]. Despite many cultural similarities, CAM services in the study of Albedah et al. still seems to be far more common, especially in reference to traditional therapists such as Hijamat (wet cupping). However, visiting with a homeopathic therapist in this study was approximately zero as well [21].

In one study in 2017 in Korea using the Korean version of I-CAM (completed by 1668 people online), visit with conventional physicians was $67.9 \%$ and with CAM providers were more than 20\% [16]. Another study in 2011 in South Korea has reported that $69.3 \%$ of the respondents had visited TKM clinics one to four times during the previous year [22]. In a similar study using the German version of I-CAM completed in 2012 by 210 individuals, $44.3 \%$ of cases had visited with a CAM provider [23].

Overall, the frequency of visits with CAM therapists in the Babol study is far lower than in other studies, if not considering herbs sellers. Visiting the traditional medicine therapist in the Babol study is also far less common than in the studies of Korea and Germany [16, 23]. However, it should be borne in mind that those studies were conducted online and nationally. Notably, a comparison with Albedah et al. study conducted in one province of Saudi Arabia also confirms the lower rate of the visit with CAM providers in Babol.

As much as $6.1 \%$ of Babol study and $11.3 \%$ of Saudi's study population had been prescribed to use CAM by the physicians and paramedics. The most frequent prescription was the use of herbs and herbal remedies (3.4 and $5.7 \%$ respectively) [18]. In the German study, 38.1, 7.2 , and $14.9 \%$ of all participants were respectively prescribed by physicians to use herbal medication, acupuncture, and homeopathy [23]. In the Korean study, the rate of the most prescribed CAM method by physicians was $12.6 \%$ for supplements and $10.8 \%$ for acupuncture [16]. A comparison of the results showed that physicians' recommendation for using CAM in Babol city is much lower than studies in Korea, Saudi Arabia, and Germany. This demonstrates the need to increase the familiarity of physicians of Babol with approved methods of CAM. However, no internal study was found to compare this data using this questionnaire.

In this study, only a total of 28 persons have used one of the methods listed in Table 3 of the original I-CAM questionnaires. Despite that, in the Saudi study, 10.7\% used relaxation and 6.7\% used meditation [22], and in the German study, more than $14 \%$ has used meditation, yoga, and Qigong methods [23]. Moreover, in the Korean study, yoga and meditation were the most frequent by 13.2 and $9.6 \%$ $[13,16]$. As previously predicted, this information showed that many people in Babol are not familiar with these methods. Other methods such as special dietary guidelines of Persian medicine (10.4\%) have been used instead.

In the Saudi study, $75 \%$ of respondents have used medicinal herbs for health and well-being over the past 12 months. In this study, about $25 \%$ of people used at least one type of vitamins and minerals including multivitamin, iron, folic acid, and B complex [21]. In the German study, $32.4 \%$ used homeopathic remedies, $40.2 \%$ used herbs and herbal remedies, and $41.2 \%$ used vitamins [23]. Overall, the use of vitamins and minerals in the Babol study sample appears to be less than the three other studies. On the other hand, the differences between the compounds used in the studies are interesting if the commonly used plants mentioned in the Saudi study are not included in the list of 40 plants in Babol.

Herbal medicine, homeopathy, chiropractic, and acupuncture were reported as the most frequently used CAM modalities in Europe [24]. The results of the Babol study comply with these results only in herbal medicine. Moreover, with regard to socio-demographics, CAM users are typically female, better-educated and middleaged. These results are somewhat consistent with Babol study results. According to some global studies, musculoskeletal problems, depression, insomnia, severe headaches or migraines and gastrointestinal illnesses were the most typical conditions associated with CAM, whereas in the Babol study most types of the examined CAM such as massage, dry cupping and water therapy have been used to improve musculoskeletal problems. Overall, it seems that the people of Babol county are 
using some types of CAM, such as medicinal herbs, to a large extent, though mostly for simple diseases such as colds and transient gastrointestinal disorders. Yet, the use of many well-known CAM therapies in the world, such as homeopathy, chiropractic, energy therapy and acupuncture, is far below the global numbers. Self-care practices such as yoga and meditation are less commonly considered. Moreover, visiting CAM therapists was also extremely low in this area and it seems that people commonly use these methods as a self-treatment. Most of the plants used also come from the surrounding environment, which results in lower costs.

Our study had some limitations. Firstly, this is a crosssectional study, so causality cannot be determined. Secondly, despite the frequent references to ask all participants, probably due to non-attendance or lack of cooperation of some, a suitable populated dispersion was not achieved in terms of education.

\section{Conclusion}

This study, which was conducted for the first time in Babol, the most populated county of the north of Iran, showed that the use of medicinal herbs for the treatment of less serious diseases is common in this area, but other methods are less common probably due to lack of familiarity and lack of access. Further studies are suggested to investigate the causes of these differences more closely.

\section{Abbreviations}

CAM: Complementary and Alternative Medicine; I-CAM-Q: International CAM Questionnaire; PM: Persian Medicine; DHS: Demographic and Health Surveys; OR: Odds Ratios

\section{Supplementary Information}

The online version contains supplementary material available at https://doi. org/10.1186/s12906-021-03281-7.

Additional file 1: Appendix 1. Logistic Regression for Self-help practices used in the last year. Appendix 2. Logistic Regression for Use of complementary medicine throughout the life.

\section{Acknowledgements}

We thank the team of interviewers and our colleagues from vice chancellor of health of Babol University of Medical Sciences who provided facilities and expertise that greatly assisted the research. We also want to thank Mohammad Ali Shams, PhD, of TEFL and assistant professor of English at Medical University of Babol for his help in English editing of manuscript.

\section{Authors' contributions}

RM designed the model of the study, performed education of interviewers and drafted the manuscript. SAM performed coordination with Babol Health Network and interviewers. MM contributed in all stages of designing the questionnaire and discussed the results and commented on the manuscript. SDN performed coordination with Babol Health Network and interviewers and contributed in all stages of designing the questionnaire. NG contributed in all stages of designing the questionnaire and discussed the results and commented on the manuscript. RS contributed in all stages of designing the questionnaire and discussed the results. FA discussed the results and commented on the manuscript. HSh contributed in all stages of designing the questionnaire, analyzed data in all stages of the study and co-wrote the paper. All authors have read and approved the manuscript.

\section{Funding}

This research was supported by National Institute of Health Research of Iran (Grant number: 241/M/96132). The cost of the executive part of the project (payment to the interviewers and their teams) was covered by the institute.

\section{Availability of data and materials}

The datasets used and/or analyzed during the current study are available from the corresponding author on reasonable request.

\section{Declarations}

Ethics approval and consent to participate

The research was approved by the research ethics committee of National Institute of Health Research (reference number: IR.TUMS.NIHR.REC.1396.53). The written informed consent was signed by every participant. For disabled persons and children under the age of 15, their legal guardians or parents signed the informed consent.

\section{Consent for publication}

Not applicable.

\section{Competing interests}

The authors declare that they have no competing interests.

\section{Author details}

${ }^{1}$ Traditional Medicine and History of Medical Sciences Research Center, Health Research Institute, Babol University of Medical Sciences, Babol, Iran. ${ }^{2}$ Healthcare Services Management, Department of General Courses, School of Medicine, Social Determinants of Health Research Center, Research Institute for Health, Babol University of Medical Sciences, Babol, Iran. ${ }^{3}$ Department of Traditional Medicine, School of Traditional Medicine, Tehran University of Medical Sciences, Tehran, Iran. ${ }^{4}$ Internal Medicine, National Institute for Health Research, Tehran University of Medical Sciences, Tehran, Iran. ${ }^{5}$ Social Determinants of Health Research Center, Health Research Institute, Babol University of Medical Sciences, Babol, Iran.

Received: 26 March 2020 Accepted: 18 March 2021

Published online: 08 April 2021

\section{References}

1. Italia S, Brand H, Heinrich J, Berdel D, von Berg A, Wolfenstetter SB. Utilization of complementary and alternative medicine (CAM) among children from a German birth cohort (GINIplus): patterns, costs, and trends of use. BMC Complement Altern Med. 2015;15(1):49. https://doi.org/10.1186/ s12906-015-0569-8.

2. Abdullah N, Borhanuddin B, Patah AEA, Abdullah MS, Dauni A, Kamaruddin MA, et al. Utilization of complementary and alternative medicine in multiethnic population: The Malaysian Cohort Study. J Evid Based Integ Med. 2018;23:2515690X18765945.

3. Lotfi M-S, Adib-Hajbaghery M, Shahsavarloo ZR, Gandomani HS. The prevalence of traditional and complementary medicine in the general population in Kashan, Iran, 2014. Eur J Integ Med. 2016;8(5):661-9. https:// doi.org/10.1016/j.eujim.2016.06.006.

4. Kemppainen LM, Kemppainen TT, Reippainen JA, Salmenniemi ST, Vuolanto $\mathrm{PH}$. Use of complementary and alternative medicine in Europe: healthrelated and sociodemographic determinants. Scand J Public Health. 2018; 46(4):448-55. https://doi.org/10.1177/1403494817733869.

5. Nilsson M, Trehn G, Asplund K. Use of complementary and alternative medicine remedies in Sweden. A population-based longitudinal study within the northern Sweden MONICA project. J Intern Med. 2001;250(3): 225-33. https://doi.org/10.1046/j.1365-2796.2001.00882.x.

6. Adib-Hajbaghery $M$, Hoseinian M. Knowledge, attitude and practice toward complementary and traditional medicine among Kashan health care staff, 2012. Complement Ther Med. 2014;22(1):126-32. https://doi.org/10.1016/j. ctim.2013.11.009.

7. Clarke TC, Black LI, Stussman BJ, Barnes PM, Nahin RL. Trends in the use of complementary health approaches among adults: United States, 2002-2012. Natl Health Stat Rep. 2015;79:1. 
8. Boccolini PMM, Boccolini CS. Prevalence of complementary and alternative medicine (CAM) use in Brazil. BMC Complement Med Ther. 2020;20(1):1-10.

9. Harris P, Cooper K, Relton C, Thomas K. Prevalence of complementary and alternative medicine (CAM) use by the general population: a systematic review and update. Int J Clin Pract. 2012;66(10):924-39. https://doi.org/1 0.1111/j.1742-1241.2012.02945.x.

10. Mosadegh M, Naghibi F. Iran Traditional Medicine: Past \& Present; 2002.

11. World Health Organization. WHO global report on traditional and complementary medicine 2019. World Health Organization; 2019. p. 105

12. Quandt SA, Verhoef MJ, Arcury TA, Lewith GT, Steinsbekk A, Kristoffersen AE, et al. Development of an international questionnaire to measure use of complementary and alternative medicine (I-CAM-Q). J Altern Complement Med. 2009;15(4):331-9. https://doi.org/10.1089/acm.2008.0521.

13. Quandt SA, Ip EH, Saldana S, Arcury TA. Comparing two questionnaires for eliciting CAM use in a multi-ethnic US population of older adults. Eur J Integ Med. 2012;4(2):e205-e11. https://doi.org/10.1016/j.eujim.2011.12.009.

14. Shumer G, Warber S, Motohara S, Yajima A, Plegue M, Bialko M, et al. Complementary and alternative medicine use by visitors to rural Japanese family medicine clinics: results from the international complementary and alternative medicine survey. BMC Complement Altern Med. 2014;14(1):360. https://doi.org/10.1186/1472-6882-14-360.

15. Bryden GM, Browne M. Development and evaluation of the RI-CAM-Q as a brief summative measure of CAM utilisation. Complement Ther Med. 2016; 27:82-6. https://doi.org/10.1016/j.ctim.2016.05.007.

16. Lee JA, Sasaki Y, Arai I, Go H-Y, Park S, Yukawa K, et al. An assessment of the use of complementary and alternative medicine by Korean people using an adapted version of the standardized international questionnaire (I-CAM-QK): a cross-sectional study of an internet survey. BMC Complement Altern Med. 2018;18(1):238. https://doi.org/10.1186/s12906-018-2294-6.

17. Davoodi $D$, Heidari F. Frequency of application of complementary and traditional medicine methods in residents of Bojnourd. Navid No. 2018; 21(67):41-52.

18. Anbari K. Use of complementary and alternative mediecine methods and its related factors in person referred to health centers in Khorramabad; 2015.

19. Kabir M, Ashrafian Amiri H, Rabiee S, Hasanzadeh Rostami Z, Farzin K, Nasrollahpour Shirvani S, et al. Level of familiarity and attitude of the covered population regarding the criteria and requirements of Iran's urban family physician program. J Babol Univ Med Sci. 2018;20(11):40-8.

20. SA TB, Asgharifard $\mathrm{H}$, Haghdoost A, Barghmadi M, Mohammadhosseini N. The use of complementary/alternative medicine among the general population in Tehran, Iran. Payesh (Health Monitor). 2008;7(4):355-62.

21. AlBedah AM, Khalil MK, Elolemy AT, Al Mudaiheem AA, Al Eidi S, Al-Yahia $O A$, et al. The use of and out-of-pocket spending on complementary and alternative medicine in Qassim province, Saudi Arabia. Ann Saudi Med. 2013;33(3):282-9. https://doi.org/10.5144/0256-4947.2013.282.

22. Woo J-M, Park E-J, Lee M, Ahn M, Kwon S, Koo KH. Changes in attitudes toward and patterns in traditional Korean medicine among the general population in South Korea: a comparison between 2008 and 2011. BMC Complement Altern Med. 2014;14(1):436. https://doi.org/10.1186/14726882-14-436.

23. Re ML, Schmidt S, Güthlin C. Translation and adaptation of an international questionnaire to measure usage of complementary and alternative medicine (I-CAM-G). BMC Complement Altern Med. 2012;12(1):259.

24. Eardley S, Bishop FL, Prescott P, Cardini F, Brinkhaus B, Santos-Rey K, et al. A systematic literature review of complementary and alternative medicine prevalence in EU. Complement Med Res. 2012;19(Suppl. 2):18-28. https:// doi.org/10.1159/000342708.

\section{Publisher's Note}

Springer Nature remains neutral with regard to jurisdictional claims in published maps and institutional affiliations.

Ready to submit your research? Choose BMC and benefit from:

- fast, convenient online submission

- thorough peer review by experienced researchers in your field

- rapid publication on acceptance

- support for research data, including large and complex data types

- gold Open Access which fosters wider collaboration and increased citations

- maximum visibility for your research: over $100 \mathrm{M}$ website views per year

At BMC, research is always in progress.

Learn more biomedcentral.com/submissions 